\title{
LA CONSTRUCCIÓN DE LAS FRONTERAS EUROPEAS COMO ORIGEN DE LA CRIMINALIZACIÓN DE LAS MIGRACIONES EN EUROPA: RETÓRICAS DE SECURITIZACIÓN Y HUMANITARISMO
}

\author{
The construction of the European borders \\ as the origin of the criminalization of migration: \\ rhetoric of securitization and humanitarianism
}

\author{
Ana Belén Estrada Gorrín* \\ María Cristina Fuentes Lara**
}

\begin{abstract}
Resumen. El presente artículo realiza un breve recorrido histórico en torno a la construcción de las fronteras exteriores de Europa a partir del tratado de Schengen (1985). La progresiva desaparición de las fronteras interiores genera un estiramiento de las fronteras europeas, las cuales se construyen como espacios dinámicos justificando su continua reterritorialización allí donde se fundamenten cómo artefacto para garantizar la seguridad, y consecuentemente entendiendo la migración hacia Europa y dentro de esta como una amenaza. La gestión de las fronteras por la Unión Europea no se vincula a un discurso de odio, si bien en la actualidad sí existe un auge de las fuerzas políticas ultraderechistas en Europa, sino que debe basarse a nivel discursivo en una retórica de seguridad, pero también de humanitarismo. Sin embargo, las fronteras, como afirma Balibar (2003), son la condición absolutamente no democrática -o discriminatoria- de las sociedades democráticas.
\end{abstract}

Palabras clave: frontera; Derechos Humanos; seguridad; violencia; discurso.

Abstract. This article provides a brief historical overview of the construction of Europe's external borders since the Schengen Agreement (1985). The progressive disappearance of the internal borders generates a stretching of the European borders, which are constructed as dynamic spaces justifying their continuous reterritorialization wherever they are based as an artefact to guarantee security, and consequently understanding migration towards and within Europe as a threat. The management of borders by the European

\footnotetext{
* Universidad de Granada. Madrid, España. E-mail: anabelesestrada@ugr.es. Orcid: 0000-00016806-3479.

** Universidad Francisco de Vitoria / Universidad Rey Juan Carlos. Madrid, España. E-mail: cristina. fuentes@ufv.es. Orcid: 0000-0003-3198-7701.
} 
Union is not linked to a discourse of hatred, although there is a rise in extreme right-wing political forces in Europe, but it must be based at the discursive level on a rhetoric of security, but also of humanitarianism. However, borders, as Balibar (2003) states, are the absolutely undemocratic -or discriminatory- condition of democratic societies.

Keywords: border; human rights; security; violence; discourse.

\section{Desde la utopía de un mundo sin fronteras hacia la fronterización}

El concepto de frontera es dinámico, y ha ido evolucionando con el devenir del tiempo. Si bien la frontera ha estado constante desde la antigüedad, sus funciones han ido modificándose, así como la forma de percibirla y conceptuarla (Balibar, 2009). La frontera es un término polisémico, se puede hacer en un sentido epistemológico, ético, psicológico, ontológico y geopolítico. Concretamente, en este último sentido de frontera es en el que se va a centrar esta investigación al estar vinculado con el poder, la soberanía, el orden, la identidad y la estabilidad (Zapata-Barrero, 2012).

La concepción rígida de la frontera como un límite geográfico y estática, tal y como se analizaba desde la border theory está totalmente superada en la actualidad (O'Neil, 1994; Riezu, 2008), puesto que la frontera es, más bien, el "resultado de un proceso dinámico, como una realidad construida política y socialmente y en permanente cambio en cuanto a su gestión de la movilidad humana" (Zapata-Barrero, 2012, p. 40), al igual que la define Lozano (2007) como "inestable, móvil y penetrable" (p. 64). Para Faist (2012), la frontera como límite que delimita dos o más sociedades es más que discutible en el actual contexto globalizador.

La globalización alteró los pilares del Estado-Nación con los efectos que acarrea, como son la conformación de redes transnacionales de migrantes, los circuitos comerciales de bienes, mercancías, información, y de actividades ilícitas -contrabando, tráfico de drogas...- etc. lo cual genera que se discuta el rol del Estado-Nación en el mundo global (Tapia, González, 2014). Sassen (2003) da un paso más, y señala que esta fase de la economía mundial viene acompañada de una deconstrucción -unbundle- de la territorialidad a favor de prácticas económicas, lo cual hace frente a la soberanía del Estado-Nación. Brown (2015) afirma que esta pérdida de soberanía, que experimenta el Estado-Nación en el contexto de una economía global, hace que los propios Estados tiendan a visibilizar sus fronteras, amurallándose, más como una teatralización del poder soberano que como un acto efectivo de proteger a un interior de un exterior cada vez más diluido, cada vez más penetrable. 
Así pues, la globalización y la economía global han influido notablemente en la concepción de la frontera como espacio dinámico (Newman, 2006), y a su vez, también está contribuyendo a una nueva configuración de la frontera cada vez más autónoma del Estado-Nación (Sassen, 2007); siendo la globalización económica quien más peso ha tenido en la concepción de la frontera en la actualidad. Esta interpretación de la frontera pone de manifiesto la capacidad de inclusión/exclusión del borderland y cómo este proceso de fronterización o la desterritorización de fronteras visibiliza la construcción de la diferencia (Newman, 2003) entre el "nosotros" y el "otros", es decir el ciudadano y el no-ciudadano; lo que Balibar (2005) califica como "doble régimen de circulación de los individuos", es decir, la distinción entre las personas que tienen más posibilidades de movimiento global y aquellos a los cuales se les restringe su libertad de movimiento.

\subsection{El dinamismo fronterizo en las sociedades globales}

La visión humanista y liberal del paradigma de un mundo sin fronteras comienza a coger forma tras la publicación de Aliens and citizens: the case for Open Borders de Joseph Carens en 1987. En el artículo no se abogaba por la supresión de fronteras políticas, sino que se centraba en los criterios de admisión y selección de migrantes en las fronteras. El mundo sin fronteras ha estado presente en los ideales del pensamiento romántico europeo, sin embargo, estos ideales decimonónicos han versado hacia la fronterización de la Unión Europea. En el nuevo paradigma en el que se encuentra el EstadoNación tras la globalización, Koff (2008) plantea tres posibilidades: el gobierno multi-escalar; el nuevo regionalismo; y el mundo sin fronteras.

En los casos del gobierno multi-escalar y del nuevo regionalismo se distinguen por ser fenómenos predominantemente europeos. Respecto al gobierno multi-escalar, un claro de ejemplo de la Unión Europea (UE) y cómo a diferencia del Tratado de Libre Comercio (TLC) y el Mercosur, la UE no solamente ha alcanzado la integración a nivel económico, sino que ha generado políticas regionales y sociales de desarrollo y cooperación entre los países miembros (Koff, 2008). En cuanto al nuevo regionalismo, este enfoque emerge por "la desterritorialización del Estado-nación que ha llevado al nacimiento de nuevas ideologías y movimientos político con base en la etnicidad, el idioma, el lugar de pertenencia, entre otros" (Koff, 2008, p. 125). En esta visión, las fronteras territoriales no son un requisito para la construcción de la identidad, como atesoran los casos de los movimientos nacionalistas en Irlanda del Norte; las minorías étnicas como los gitanos en la Europa del Este; y las "naciones sin estados" como los québecois o los vascos (Keating, 2001).

En tercer lugar, Koff (2008) afirma que la idea de un mundo sin fronteras surge porque las actividades socioeconómicas -globalización económica- 
y políticas -integración regional-, ya no están limitadas por las fronteras del Estado-Nación. Más bien son las redes trasnacionales quienes controlan las actividades económicas y sociopolíticas (Sassen, 2000; Ohmae, 1990). Al igual que señala Newman (2006) quien apunta que "para muchos, la noción de un mundo desterritorializado y sin fronteras ha llegado a ser una nueva forma para nombrar a la globalización" (p. 1). La idea de un mundo sin fronteras no debería percibirse como una utopía. En un mundo global donde el mercado y la economía global han reducido al mínimo la capacidad decisoria del EstadoNación (Sassen, 2000, 2003, 2007; Ohmae, 1990), es solamente la movilidad humana la única barrera fronteriza (Velasco, 2010, 2012; Carens, 1987, 2002; Kymlicka, 2006). Bauman (2001) señala que la libre circulación de personas es un bien codiciado al ser un factor de distinción y estratificación social. De tal forma, es correcto afirmar que la soberanía del Estado-Nación y de las fronteras políticas se mantienen porque cumplen la función de control de la libre circulación de migrantes, de hecho, Sassen (2010) asegura que la inmigración es un campo de prueba privilegiado para testar los límites normativos del Estado-Nación, así como de sus contradicciones y sus tensiones internas. Al hilo de esta idea, Velasco (2012) reflexiona sobre que sería más idóneo hablar de "un mundo con fronteras abiertas" con la libre circulación de personas, en lugar de "un mundo sin fronteras" por lo utópico de la expresión. Para Kymlicka (2006) "aunque los Estados puedan conservar sus límites territoriales, estos no deben constituir obstáculos para la movilidad; y el derecho a vivir y trabajar dentro de un Estado no debe depender del lado de la frontera en que se haya nacido" (p. 37-38).

\subsection{La estructuración de las fronteras. El caso de la Unión Europea}

En la década de los 80 en Europa comenzó un proceso de eliminación de las fronteras entre los países del continente. Este fenómeno fue impulsado por la Comunidad Económica Europea $(\mathrm{CEE})^{1}$. En un primer momento, este proceso se interpretó con optimismo, puesto que simbolizaba el acercamiento entre las dos Europas -oeste y este- (Tapia, González, 2014); y, además, la visión liberal suponía un impulso hacia el ideal de un mundo sin fronteras.

El Acuerdo Schengen fue el inicio del cambio de paradigma de gestión de las fronteras en la Unión Europea. El primer Acuerdo Schengen se firmó en 1985, entre los países de Alemania, Bélgica, Francia, Luxemburgo y Países Bajos. En el acuerdo únicamente se establecía una cooperación transfronteriza entre los países firmantes, fue ya en el segundo acuerdo en 1989, donde se avanzó hacia la idea de crear un área libre de fronteras y de desmantelar los controles fronterizos internos (Spencer, 1990). Si bien el acuerdo se firmó

1 A partir del Tratado de Maastricht (1992) la CEE pasó a denominarse Unión Europea. 
en el 1990, la entrada en vigor se retrasó hasta la firma del Convenio de Aplicación de 1994. Los motivos se centraron en la aplicación de la libertad de circulación entre los países firmantes, a lo que se le unió que la Unión Europea (UE) no tenía competencias para desarrollar procedimientos referentes a terrorismo, nacionalidad y migración; lo cual suponía dejar su implementación al amparo de los países firmantes. Concretamente, Reino Unido fue especialmente crítico con la gestión de la movilidad de personas que reflejaba Schengen ${ }^{2} ;$ y, finalmente decidió no adherirse al acuerdo. En el caso opuesto, los países que se adhirieron a Schengen, antes de su entrada en vigor, fueron Italia (1990), Portugal y España (1991) y Grecia (1992). Si bien finalmente se logró que se implementara el Acuerdo Schengen, este incluyó controles fronterizos rigurosos para la ciudadanía no-Schengen y se creó un Sistema de Información de Schengen para fomentar la colaboración entre los países del espacio Schengen (Sassen, 2014).

La eliminación de fronteras internas que se desarrolló a partir del Acuerdo Schengen tuvo una repercusión en la gestión de las fronteras externas del espacio Schengen. En primer lugar, el Tratado de Maastricht (1992) desarrolló la primera estructura formal sobre los requisitos legales para las migraciones internacionales con destino en los países de la Unión Europea. Esto fue el germen para iniciar los alineamientos para una política común de visados. Además, en Maastricht se establecieron los tres pilares de la UE: el comunitario, la Política Exterior y de Seguridad Común (PESC); y la Cooperación en Justicia y Asuntos de Interior (CJAI). En este último es en el que se encuadraron las materias relativas a migración y asilo. En segundo lugar, el Tratado de Ámsterdam (1997) en el que se creó el Espacio de Libertad, Seguridad y Justicia (ELSJ), que introduce políticas de control y cooperación con terceros países en asuntos de migración y gestión de fronteras. Este Tratado también pasa las competencias de control de fronteras exteriores, de migración y asilo del tercer pilar de la UE al primero, con la finalidad de que las decisiones de la UE en estas áreas fueran vinculantes para los Estados miembros (Saceda, 2016; Argerey, 2005). Las conclusiones del Tratado de Ámsterdam se trasladaron al Consejo Europeo de Tampere (1999), en cual marcó el enfoque europeo sobre fronteras y migración. En las actas del Consejo Europeo de Tampere se señala que:

La Unión ha de desarrollar políticas comunes en materia de asilo e inmigración, teniendo en cuenta al mismo tiempo la necesidad de llevar a cabo un control coherente de las fronteras exteriores para poner fin a la inmigración ilegal y para luchar contra quienes la organizan y cometen delitos internacionales conexos. (1999, p. 2)

\footnotetext{
2 Esta reivindicación que se mantuvo con el paso del tiempo. De hecho, fue uno de los pilares de la campaña del referéndum sobre la permanencia del Reino Unido en la Unión Europea (2016), conocida como Brexit.
} 
El Consejo de Tampere sintetiza las políticas comunes de inmigración en una estrategia de colaboración con los países de origen, creación de una política común de asilo, un trato justo a la ciudadanía de terceros países residentes en la Unión y la gestión eficaz de los flujos migratorios (Mochel, 2004). Estas medidas se detallaron en la "Agenda de Tampere" donde se insistió en el control de los flujos y en la seguridad, priorizándolas sobre las acciones de cooperación al desarrollo e integración (Olmos, 2009). De la tal forma, que las "políticas comunes en inmigración y asilo se basaron en la necesidad de un control consistente de las fronteras exteriores para detener la inmigración ilegal y combatir a quienes la organizan y comenten crímenes relacionados" (Pinyol, 2012, p. 262). Es a partir de este momento, cuando las políticas migratorias de la UE se centraron en el control y en la criminalización del migrante indocumentado (Quraishi, 2005; Ortega-Pérez, 2003). El Colectivo IOE (2001) reflexiona cómo el "espíritu de Schengen", no es otra cosa que desconfiar de las personas migrantes asentadas en Europa, y rechazar a quienes intentan llegar; haciendo ver que la inmigración un "problema" y una "amenaza". Si bien con Schengen se liberaron las fronteras internas, esto se produjo a costa de endurecer las externas (Driessen, 1998).

En este breve recorrido histórico político de la gestión migratoria de la UE desde el primer acuerdo Schengen (1989) hasta la Agenda Tampere (1999), se pasa de una visión optimista de un mundo sin fronteras en el que no existen controles fronterizos internos a, en tan solo una década, la Europa fortaleza en la que el migrante es criminalizado por el simple hecho de migrar, que es un derecho recogido en la Declaración Universal de Derechos Humanos (DUDH) (1948), que el artículo 13 señala que "toda persona tiene derecho a circular libremente y a elegir su residencia en el territorio de un Estado. Toda persona tiene derecho a salir de cualquier país, incluso del propio, y a regresar a su país"; lo cual no deja de ser una paradoja, ya que como afirma Heller (1992) emigrar es un derecho humano según la DUDH, mientras que inmigrar no lo es, y, es más, está penalizado, perseguido y criminalizado en la Europa Fortaleza. El caso europeo no es una excepción, en la frontera de México y Estados Unidos se ha ido fortaleciendo militarmente los pasos fronterizos en las últimas décadas. Tapia y González (2014) afirman que el origen de la securitización europea se produce con los ataques terroristas del $11-S$ y el comienzo de la "era del terror". Sin embargo, como se ha visto en este apartado, la tendencia a la Europa fortaleza es anterior al 11-S de 2001, ahora bien, el clima internacional sirvió de pretexto para consolidar las ideas y las acciones de la securitización que ya se estaban produciendo en la Unión Europea (De Lucas, 2002; López-Sala, 2005; Ferrer-Turrión, López-Sala, 2012). Zolberg (2002), en esta misma idea, afirma que tras el 11-S algunos países europeos y Estados Unidos se acogen al "enfoque clásico westfaliano 
ante la demanda de un plan de choque, para fortalecer la capacidad de vigilar (...) los territorios fronterizos para identificar y neutralizar a los enemigos de origen foráneo" (p. 1); o lo que es lo mismo, se produce una identificación entre el migrante laboral y terrorista que ha securitizado la frontera europea (White, 2003).

\subsection{La fronterización de la Unión Europea}

La Europa fortaleza o fortaleza europea es un concepto que hace referencia a las políticas paulatinas de fronterización de la Unión Europa; y para describir el actual funcionamiento del régimen migratorio europeo (Rigo, 2007; Mezzadra, 2005; De Lucas, 1996). El término es conceptualizado por autores de los estudios de frontera, para Zapata-Barrero (2010) la Europa fortaleza es una representación que "evoca el símbolo medieval de un castillo que protege su población frente a los peligros externos" (p. 14), En esa línea se encuentra Ferrer-Gallardo (2008) quien valora el término como una metáfora inconcreta para describir la política migratoria europea; mientras que para López-Sala (2005) este concepto no es preciso. La autora señala que no se puede hablar de Europa Fortaleza porque no existe ni un cierre total ni una política migratoria de cero entradas en la Unión Europea, puesto que existe la reagrupación familiar, las solicitudes de asilo y la entrada de los trabajadores cualificados. Sin refutar a López-Sala, cabe destacar que la lentitud de la burocracia y la arbitrariedad de los países de la UE para aceptar solicitudes, hacen que la entrada "legal, regulada o documentada" por asilo o reagrupación familiar no sean procedimientos exitosos, respecto al número de solicitudes recibidas (Fuentes-Lara, 2018), este sería el ejemplo del número de solicitudes tramitadas y aceptadas en la conocida como "crisis de los refugiados" de 2015 (Karageorgiou, 2016) por la llegada de un millón de personas, desplazadas forzosamente por los conflictos bélicos en Oriente Próximo y África, quienes esperaban encontrar asilo político en Europa, a la que intentaban llegar a través de las costas griegas y la ruta de los Balcanes. Cabe preguntarse ¿cuándo empieza la fronterización europea? La comunidad académica no llega a un consenso. Para algunos autores, comienza con el Acuerdo Schengen al iniciarse una visión más securitaria de las políticas migratorias (Bigo 2000; Pedone, 2001). En el caso español, y concretamente el de Ceuta y Melilla con la entrada en la Unión Europea y la adhesión al Acuerdo Schengen los enclaves españoles en África se convirtieron en la frontera sur europea. No es casual que la Unión Europea reforzarse, con especial interés, la frontera hispano-marroquí, al considerarla como una de las más porosas de Europa (Pérez, 2012, p. 161), es más, aún ahora la UE la sigue considerando como porosa (Fuentes-Lara, 2018). Existe una segunda vertiente de pensamiento que sitúan el inicio de la fronterización europea 
con el Tratado de Ámsterdam y el Congreso Europeo de Tampere (Naranjo, 2014; Zapata-Barrero, 2012). Las medidas acordadas en estas cumbres como fueron: los alineamientos comunes en visados, la cooperación policial y judicial, la política de asilo, y la criminalización del migrante indocumentado refrendada por la lucha antiterrorista (Mora, Montenegro, 2009; Santamaría, 2002) primaron la fronterización a la integración, que quedó reservada para las personas migrantes en situación administrativa regular (Naranjo, 2014).

Independientemente del inicio de la fronterización europea, ya sea Schengen, Ámsterdam o Tampere, a partir de ahí se han desarrollado acciones de la UE para la construcción de la Europa Fortaleza. Comenzando por el Consejo Europeo de Laeken en 2001 en que el que se aprobó el Plan Global de lucha contra la inmigración ilegal. Este Plan consistía en apoyar económicamente a los países de origen y tránsito de las personas migrantes con la finalidad de frenar la llegada de migrantes indocumentados (Gil, 2011); esta medida era una novedad respecto al Congreso de Tampere. Un año después, en el Consejo Europeo de Sevilla se empezaron a desarrollar las medidas de securitización de las fronteras exteriores de la UE. Mediante acciones coordinadas de los países miembros se impulsó un incremento de la seguridad en las fronteras exteriores de la UE, lo que para Pérez (2012), este Congreso es el antecedente de la Agencia Europea de Frontera (FRONTEX). En 2003, se celebró el Consejo Europeo de Tesalónica que implementó la Política Europea de Vecindad (PEV), cuya finalidad era una política centrada en los preceptos de migración y desarrollo en terceros países, pero que en la práctica se ha materializado como un instrumento para "financiar" la externalización de fronteras (Godfrey et al., 2014) por medio de fondos a estos terceros países para que frenen -de cualquier forma- a las personas en tránsito migrante. Un claro ejemplo de la PEV es la frontera hispano-marroquí, donde con los fondos de la PEV se desarrolló en 2005 el Plan de Acción entre Marruecos y la Unión Europea. En este Plan, Marruecos se compromete a cumplir con las reformas y las medidas que le exija la Unión, a cambio de recibir fondos económicos en concepto de "cooperación al desarrollo" (Saceda, 2016; Kausch, 2010).

La política migratoria de la UE está orientada a la externalización y a la securitización de las fronteras externas. Respecto a la externalización de fronteras de la Unión Europea, se caracteriza por la gestión de flujos migratorios en los países de origen y tránsito de los migrantes, antes de llegar a los Estados receptores de la Unión -principalmente España, Italia y Grecia- (RemiroBrotóns, 2012; Kramsch, 2009). Esta estrategia viene acompañada -o generaun proceso de desterritorialización de las fronteras europeas, que trasciende sus funciones de control y seguridad de la acción nacional y supranacional (Ferrer-Turrión, López-Sala, 2012). La externalización de fronteras exige una colaboración directa o indirecta, de los países emisores y de tránsito de 
migrantes, convirtiendo a Marruecos, Libia, Argelia, Túnez, Mauritania y Turquía en la frontera exterior de la Unión Europea (Ferrer-Gallardo, Zapata-Barrero, 2012). La UE con el propósito de incentivar la cooperación de estos países de la "lucha contra la inmigración irregular", dota de fondos económicos a los Estados para emprender reformas en el país, acuerdos comerciales con la UE, creación campos o centros para demandantes de asilo y cuotas de migración legal para nacionales de estos países colaboradores (Naranjo, 2014).

La externalización de fronteras delega la responsabilidad a terceros países, del control y la gestión de los flujos migratorios a cambio de un trato preferencial con la UE, pero también condicionando la gestión de la migración como un requisito imprescindible para mantener o adoptar acuerdos económicos y comerciales con la Unión Europea (Ferrer-Gallardo, Kramsch, 2012). De tal modo, que los países origen y tránsito de migrantes se convierten en los "gendarmes europeos" a cambio de fondos económicos y un trato comercial preferencial, si realizan bien su labor (López-Sala, 2012). A la vez que se externaliza la gestión de flujos, también se produce la paulatina externalización de los controles fronterizos, dando lugar a una "policía a distancia" (Gil, 2003), o como señalan Soriano-Miras et al. (2016) la Unión Europea ha construido una frontera nueva, lejana e invisible, con la finalidad de ocultar la realidad existente. La Comisión Europea respecto a este escenario internacional generado por la llegada de migrantes y refugiados a las costas europeas en 2015, periodo referido como "crisis de los refugiados", reafirmó su posición de Europa fortaleza:

Para devolver lo antes posible la normalidad al funcionamiento del espacio de Schengen y se requieren la adopción de una serie de medidas importantes. En primer lugar, todos los Estados miembros deben acatar las normas: es preciso poner fin a la política de permitir el paso. Además, los Estados miembros deben conceder acceso a los solicitantes de asilo, pero denegar la entrada a quienes tengan meros fines de tránsito. En segundo lugar, hemos de subsanar las graves deficiencias detectadas en nuestras fronteras exteriores, pues obviamente nuestro espacio interior libre de controles fronterizos solo puede existir si protegemos firmemente nuestras fronteras exteriores. (Comisión Europea, 2016)

La Comisión Europea señala dos puntos, los países miembros no pueden denegar el derecho al asilo, pero sí que tienen que diferenciar entre las personas en tránsito -migrantes indocumentados- y refugiados. Por otro lado, insta a los países europeos de la necesidad de reforzar las fronteras exteriores -securitización- ante la porosidad detectada por la Comisión, es decir, la Unión Europea no solo está incumpliendo su compromiso con el derecho al asilo, sino que la decisión de externalizar las fronteras del norte del Mediterráneo responde a la necesidad de "dar carpetazo al tema de los refugiados y los migrantes sirios, afganos, iraquíes, marroquíes y todo aquel que quisiera intentar llegar al viejo continente" (Rodríguez, 2016, p. 56). 


\section{La aplicación de la Europa Fortaleza en los movimientos migratorios}

Europa ha ido firmando una serie de acuerdos con países terceros para frenar la migración, constituyendo diferentes estados tapón a lo largo de las costas del Mediterráneo. En el acuerdo de Europa con Turquía, firmado el 16 de marzo 2016, se le concede la dudosa calificación de "tercer país seguro", donde los migrantes pueden ser devueltos si intentan llegar a Europa de manera irregular (Campani, 2019). Turquía recibe inicialmente 3.000 millones de euros en su ejercicio de frenar la migración ilegal, además de un proyecto de extinción del visado para los nacionales turcos que accedan al espacio Schengen y el aceleramiento de los trámites de la adhesión de Turquía a la UE. La "crisis de los refugiados" fue una excelente definición, no para el aumento de llegadas de personas y el aumento de muertes en el Mediterráneo, sino para el tipo de gestión migratoria empleado por la UE. El empleo de la calificación de "crisis", en un sentido humanitario, permitió una mayor flexibilidad en la gestión de los flujos migratorios a la hora de tomar medidas extraordinarias. Del mismo modo, se jerarquizó a las personas en proceso de movilidad entre migrantes "no deseados" -también catalogada como migración económicay migrantes que podrían acogerse, tomando como criterio únicamente su nacionalidad, a la protección internacional de asilo; entre este último grupo favoreciendo a las personas con nacionalidad siria frente a afganos, eritreos e iraquíes, en cuyos países también existen conflictos bélicos (García, 2018).

En 2017, Italia firmó un acuerdo multimillonario con Libia, de un país en Guerra Civil desde 2014, para proporcionar dinero, formación y embarcaciones a los guardacostas libios capacitándolos para ser más eficaces en la tarea de interceptar a los migrantes en el Mediterráneo, evitando así que lleguen a costas europea (De Lucas, 2017). En junio de 2018, la Unión Europea estableció la asignación de 1,84 millones de euros para el Fondo de Seguridad Interior, para apoyar las operaciones italianas. El resultado fue que a partir de julio de 2017 se desplomaron las llegadas a Italia, que pasó de recibir 180.000 migrantes al año a los cerca de 10.000 en 2019. El precio lo pagaron otras 40.000 personas fueron devueltas desde entonces a Libia, donde han sufrido de nuevo todo tipo de maltratos en los centros de detención, como han documentado las agencias de Naciones Unidas (Acosta, 2019).

En 2018, se produce la cifra más alta de llegada de migrantes a España de toda serie histórica, con un número de 64.120 personas según los datos de seguimiento de la APDHA (2019) que incluye todas las llegadas por las fronteras marítimas en el litoral español (costas peninsulares, insulares, Ceuta y Melilla y llegadas en los buques de Acuarius y Open Arms) y las fronteras terrestres de Ceuta y Melilla. El número de Ilegadas continúa en ascenso 
desde 2016 con 14.108 llegadas, y 2017 con 28.587 (Rosado-Caro et al., 2019). Este aumento instaura la ruta entre Marruecos y España, en 2018, como la ruta de mayor tránsito con relación a todas las costas europeas, algo que era ya previsible al someter a un bloqueo mayor las rutas del centro y este del Mediterráneo, por los acuerdos entre la Unión Europea con Turquía y con Libia.

Estos tratados que ha ido externalizando las fronteras Europeas y dejando en manos de terceros países la gestión migratoria del continente, para no tener así que garantizar ningún derecho a quienes migran, ni siquiera el derecho a la vida, han ido haciendo del Mar Mediterráneo un cementerio. Hacia el interior de Europa el discurso del odio hacia las personas migrantes ha ido en aumento. Garrido (2012) muestra que los avances en política migratoria de la UE no han venido acompañados de una apertura social, sino que más bien, han generado actos racistas y conflictos sociales interraciales. La fortificación de Europa ha supuesto una creciente politización de las migraciones. Arango sitúa la manifestación de la centralidad de la migración y el asilo en la arena política principalmente en el crecimiento del apoyo electoral a las fuerzas políticas ultranacionalistas y populistas, las cuales han alcanzado posiciones de poder gracias al empleo de la retórica en contra de la inmigración (Arango et al., 2018).

Sin embargo, la politización de las migraciones no debe observarse únicamente en el crecimiento actual de las fuerzas políticas ultraderechistas en Europa, con una clara retórica antimigratoria y xenófoba, sino en el propio proceso de fortificación europea que hemos venido desarrollando. Es decir, la propia construcción de fronteras se ha realizado sobre un discurso de securitización que criminaliza a los migrantes, así como mediante un humanitarismo que, como veremos aquí, es fundamental para mantener una coherencia discursiva acorde con los valores democráticos de los Estados europeos (PorCausa, 2019). Algo profundamente contradictorio si tenemos en cuenta, como afirma Balibar (2003) que las fronteras son "la condición absolutamente no democrática o discriminatoria de las instituciones democráticas" (p. 176).

Balibar (2003) argumenta que la construcción de Europa se ha formado sobre mecanismos de exclusión materializados en las fronteras y en las prácticas institucionales correspondientes, lo cual le lleva a hablar de un verdadero apartheid europeo. Este apartheid larvado tiene su correlato en la distribución de la violencia mundial, que segmenta el mundo entre las "zonas de vida" (de buena vida) y las "zonas de muerte" (normalmente de muerte sucia), y que debe ser llamada exterminismo, clasificando a los individuos, según estén a un lado u otro de la línea de demarcación, entre "humanidad" y "sub-humanidad" (Balibar, 2003, p. 201). Esta violencia extrema e institucionalizada no es una 
novedad en la historia, lo que tiene de novedad es la espectacularización de la misma a través de "una industria mediática de representación de la violencia que constituye uno de los incentivos de la 'depauperización cultural' y, por tanto, de la decadencia política democrática" (Balibar, 2003, p. 201).

En las fronteras europeas podemos observar con gran claridad el encuentro de dos lógicas de violencia institucionalizada, pues en ellas se "perpetúa al exterior de la frontera la violencia imperialista con el fin de garantizarse 'al interior' el monopolio de la violencia legítima" (Balibar, 2003, p. 202). Esta idea revierte en la formulación según la cual las fronteras no son meramente la línea divisoria entre dos Estados, sino que "siempre es sancionada, reduplicada y relativizada por otras divisiones geopolíticas", remitiendo a un orden global previo a su trazado y que llevan a cabo "una función de configuración del mundo" sin la cual "no habría fronteras, o fronteras duraderas" (Balibar, 2003, p. 201). Las fronteras son establecidas institucionalmente como una "zona de muerte", por lo que visibiliza la violencia establecida a nivel global; pero a su vez, al ser un espacio de transición que toca a los "estados garantes de derechos", especialmente de los Derechos Humanos, los estados europeos deben ocultar, y al mismo tiempo legitimar mediante prácticas discursivas, la violencia en ellas ejercida. Irónicamente es a través de discursos sobre una ética de los Derechos Humanos, a la par que la criminalización de los migrantes, como se legitima la violencia de los Estados en las zonas fronterizas.

La retórica de los derechos humanos, así como la retórica de la seguridad, divide el movimiento migratorio entre traficantes, criminales y víctimas, las formas de representación más habituales en los discursos públicos sobre migración (Bañón, 2002). Se emplean discursos que generan representaciones para justificar sus propias acciones de represión, así como para hacer visible, y por tanto regulable, el exceso de movilidad en las migraciones. La representación es otro modo de intentar regularizar las subjetividades migrantes, es decir, es también una herramienta de control empleada para organizar y contener los conflictos sociales. La representación no es otra cosa que el significado de hacer de las fuerzas que participan en un conflicto social algo visible a la mirada del poder: hace a los actores representables dentro de un régimen (Papadopoulos et al., 2008). La representación es por tanto una forma de poder organizada como espectáculo. Con esta idea de espectáculo no nos referimos simplemente a una colección de imágenes, representaciones y abstracciones, sino que tiene además la capacidad de mediar las relaciones sociales (Debord, 2012).

La diversificación de actores que intervienen en las prácticas de control fronterizo, como el caso de las ONGs humanitarias, resultan cruciales en la inclusión del discurso de los derechos humanos, a la vez que inciden en la despolitización de las políticas migratorias. Que el discurso del humanitarismo 
atraviese a muchos de estos actores hace que para los gobiernos estos puedan funcionar como recursos: al citar su participación en las iniciativas de control de la migración consiguen aminorar las críticas (Mezzadra, Neilson, 2017). El discurso de los Derechos Humanos en la gestión de las migraciones puede ser empleado tanto para facilitar, como para bloquear o ralentizar el cruce de fronteras. A estas asociado a la gestión este se internaliza cada vez más en el propio ejercicio del poder. "A pesar de que los derechos humanos solían ser considerados como externos al ejercicio del poder, como un elemento crucial en el sistema de pesos y contrapesos que mantiene el poder a raya, estos se están transformando cada vez más en un componente clave en los regímenes de fronteras y de migración a lo largo del mundo" (Mezzadra, Neilson, 2017, p. 227). El papel del humanitarismo en el control de fronteras es un discurso que atraviesa a distintas prácticas, actores, instituciones y razones sociales involucradas en el mismo. El mismo empleo del término crisis, antes citado, alude a una crisis humanitaria la cual hace que, en última estancia, el discurso humanitarista flexibilice la aplicación de medidas extraordinarias en la gestión de fronteras.

Otra tendencia actual en Europa es acusar de tráfico de seres humanos a personas u organizaciones que rescatan a migrantes y refugiados del mar, lo cual parece una nueva etapa en el proceso europeo de control de fronteras. Un reciente informe de Amnistía Internacional (2020) ha documentado casos de restricción y criminalización de la ayuda y la solidaridad con personas en movimiento en ocho países: Croacia, España, Francia, Grecia, Italia, Malta, Reino Unido y Suiza. De este modo, también se criminaliza la solidaridad, aquella que vela por los derechos y la vida de los migrantes en los cruces de fronteras, que con sus actos pone de relieve la violencia ejercida en las fronteras.

\section{Reflexiones finales}

Si bien las actividades económicas y sociopolíticas están conformadas según redes transnacionales, haciendo de la globalización un sinónimo de un mundo sin fronteras, la movilidad humana se constituye como barrera fronteriza, haciendo que las migraciones sean un punto privilegiado para contrastar las contradicciones que los propios Estados o comunidades transnacionales manifiestan. En relación a la Unión Europea, la contradicción se acentúa: si bien a partir del acuerdo Schengen en 1985 se comienza un proceso de eliminación de las fronteras interiores de Europa, las fronteras externas se refuerzan hasta el punto de que se construye los que se ha llamado una Europa Fortaleza. Las fronteras operan a un nivel representacional, que se va uniendo progresivamente al concepto de defensa, securitización y consecuentemente entendiendo la migración hacia Europa y dentro de esta como una amenaza a la seguridad. 
Las migraciones han marcado el discurso político en Europa, pero esto no debe observarse únicamente por el crecimiento de las fuerzas políticas ultraderechistas en Europa, sino a través del propio proceso de fortificación europea que hemos desarrollados aquí. Además de la securitización, el humanitarismo es fundamental para mantener una coherencia discursiva acorde con los valores democráticos de los Estados europeos. Control y representación han sido identificados aquí como los dos dispositivos de frontera empleados para regular la movilidad en las migraciones, para tirar la piedra y esconder la mano.

\section{Referencias bibliográficas}

ACOSTA, Miguel. La formación de guardacostas libios: hacia un modelo de sinergia de políticas en la gestión integrada de fronteras marítimas europeas. Revista de Derecho Comunitario Europeo, v. 64, p. 859-895, 2019.

ARGEREY, Patricia. El impacto económico de la inmigración europea. Estudio de un caso particular: España. Madrid: Universidad Complutense, 2005.

AMNISTÍA INTERNACIONAL. Castigo a la c. La solidaridad a juicio en la fortaleza europa, 2020. Disponible en: <https://www.amnesty.org/es/documents/eur01/ 1827/2020/es/>. Acesso en: 10.05.2020.

ARANGO, Joaquín; MAHÍA, Ramón; MOYA MALAPEIRA, David; SÁNCHEZMONTIJANO, Elena. Introducción: inmigración y asilo, en el centro de la arena política. Anuario CIDOB de la Inmigración, p. 14-26, 2018.

APDHA. Derechos humanos en la frontera sur. 2019. Disponible en: <https://www. apdha.org/wp-content/uploads/2019/02/informe-frontera-sur-2019-web.pdf>. Acceso en: 10.05.2020.

BALIBAR, Étienne. Fronteras del mundo, fronteras de la política. In: BALIBAR, Étienne. Nosotros iciudadanos de Europa?. Madrid: Tecnos, 2003, p. 165-182.

BALIBAR, Étienne. Violencias, identidades y civilidad. Barcelona: Gedisa, 2005.

BALIBAR, Étienne. Violencias, identidades y civilidad. Para una cultura política global. Barcelona: Gedisa, 2009.

BAÑÓN, Antonio Miguel. Discurso e inmigración: propuestas para el análisis de un debate social. Editum, 2002.

BAUMAN, Zygmunt. La sociedad individualizada. Madrid: Cátedra, 2001.

BIGO, Didier. When Two Become One: Internal and External Securitisations in Europe. In: KELSTRUP, Morten; WILLIAMS, Michael (eds.). International Relations Theory and the Politics of European Integration, Power, Security and Community. Londres: Routledge, 2000, p. 171-204.

BROWN, Wendy. Estados amurallados, soberanía en declive. Barcelona: Herder, 2015.

CAMPANI, Giovanna. La migración europea y la crisis de los refugiados: un proceso complejo y multifacético/European migration and refugees crisis: A complex and multifaceted process. Collectivus, v. 6, n. 1, p. 15-33, 2019. 
CARENS, Joseph. Aliens and Citizens: The case for open borders. Review of Politics, n. 49, p. 251-273, 1987.

CARENS, Joseph. Inmigración y justicia, ¿a quién dejamos pasar? Isegoría, n. 26, p. 5-27, 2002.

COMISIÓN EUROPEA. Restablecer Schengen: la Comisión propone una hoja de ruta para reimplantar un sistema de Schengen totalmente operativo. Disponible en: <https://ec.europa.eu/commission/presscorner/detail/es/IP_16_585>.Acceso en: 29.06.2020.

CONSEJO EUROPEO DE TAMPERE. Conclusiones de la Presidencia, 15 y 16 de octubre de 1999.

DE LUCAS, Javier. Puertas que se cierran: Europa como fortaleza. Barcelona: Icaria Editorial, 1996.

DE LUCAS, Javier. Sobre las políticas de inmigración en la Unión Europea un año después del 11 de septiembre de 2001. Inmigración, derechos y ciudadanía [en línea]. Cuadernos Electrónicos de Filosofía del Derecho, n. 6, 2002.

DE LUCAS, Javier. Negar la política, negar sus sujetos y derechos (Las políticas migratorias y de asilo como emblemas de la necropolitica). Cuadernos Electrónicos de Filosofía del Derecho, v. 36, p. 64-87, 2017

DEBORD, Guy. Society of the Spectacle. Bread and Circuses Publishing, 2012.

DRIESSEN, Henk. The "new inmigration" and the transformation of the EuropeanAfrican frontier. In: WILSON, Thomas; DONNAN, Hasting. Border Identities. Cambridge: University Press, 1998, p. 96-116.

FAIST, Thomas. Toward a transnational methodology: methods to address methodological nationalism, essentialism, and positionality. Revue européenne des migrations internationals, n. 28, p. 51-70, 2012.

FERRER-GALLARDO, Xavier. Acrobacias fronterizas en Ceuta y Melilla: explorando los perímetros terrestres de la Unión Europea en el continente africano. Documents d'Anàlisi Geogràfica, n. 51, p. 129-149, 2008.

FERRER-GALLARDO, Xavier; KRAMSCH, Oliver. El archipiélago-frente Mediterráneo: fractura, ensamblaje y movimiento en el contorno sur de la UE. In: ZAPATA-BARRERO, Ricard; FERRER-GALLARDO, Xavier (eds.). Fronteras en movimiento. Migraciones hacia la Unión Europea en el contexto Mediterráneo. Barcelona: Bellaterra, 2012, p. 79-104.

FERRER-TURRIÓN, Ruth; LÓPEZ-SALA, Ana M. Fronteras y seguridad en el Mediterráneo. In: ZAPATA-BARRERO, Ricard; FERRER-GALLARDO, Xavier (eds.). Fronteras en movimiento. Migraciones hacia la Unión Europea en el contexto Mediterráneo. Barcelona: Bellaterra, 2012, p. 229-254.

FUENTES-LARA, M. Cristina. La fronterización o desterritorización de la frontera hispano-marroquí. La singularidad de Ceuta. Revista de Derecho Migratorio y Extranjería, v. 49, p. 69-88, 2018.

GARCÍA, Toché. El acuerdo de la ignominia: UE - Turquía. APDHA. Informe derechos Humanos en la Frontera Sur 2018. Asociación Pro Derechos Humanos en Andalucía, 2018. 
GARDUÑO, Everardo. Antropología de la frontera, la migración y los procesos transnacionales. Frontera Norte, n. 15, p. 65-90, 2003.

GARRIDO, Pedro. Inmigración y diversidad cultural en España: un análisis histórico desde la perspectiva de los derechos humanos. Salamanca: Universidad de Salamanca, 2012.

GIL, Sandra. Las migraciones en las políticas de la fortaleza. Sobre las múltiples fronteras de la Europa comunitaria. In: GIL, Sandra; DAHIRI, Mohammed (eds.). Movimientos migratorios en el Mediterráneo occidental iun fenómeno o un problema? Córdoba: Ayuntamiento de Córdoba, 2003, p. 31-58.

GIL, Sandra. Migración internacional, seguridad y desarrollo en las políticas migratorias de la unión europea (o de cómo desplazar las fronteras de Europa). IV Congreso de Migraciones y Desarrollo, FLACSO México, Ciudad de México, 18, 19 y 20 mayo de 2011.

GODFREY, Richard; BREWIS, Jo; GRADY, Jo; GROCOTT, Chris. The private military industry and neoliberal imperialism: Mapping the terrain. Organization, n. 21, p. 106-125, 2014.

HELLER, Agnes. Diez tesis sobre la inmigración. El País. 30 de mayo de 1992.

KARAGEORGIOU, Eleni. Solidarity and sharing in the common european asylum system: The case of syrian refugees. European Politics and Society, n. 17, p. 196221, 2016.

KAUSCH, Kristina. El estatuto avanzado de Marruecos: ¿Qué significado tiene? Policy brief, n. 34, p. 14-35, 2010.

KEATING, Michael. Plurinational Democracy: Stateless Nations in a Post-Sovereignty Era. Oxford: Oxford University Press, 2001.

KOFF, Harlan. La política fronteriza comparada y las estructuras del poder. Estudios políticos, n. 32, p. 119-134, 2008.

KRAMSCH, Oliver. Tropicalizando a Foucault desde la frontera europea. Latitud Sur, n. 4, p. 113-135, 2009.

KYMLICKA, Will. Fronteras territoriales. Madrid: Editorial Trotta, 2006.

LÓPEZ-SALA, Ana M. Inmigrantes y Estados: la respuesta política ante la cuestión migratoria. Barcelona: Anthropos, 2005.

LÓPEZ-SALA, Ana M. Donde el sur confluye con el norte: movimientos migratorios, dinámica económica y seguridad en las relaciones bilaterales entre España y Marruecos. Documentos CIDOB. Migraciones, n. 24, p. 1-12, 2012.

LOZANO, Jorge. En los límites. Fronteras y confines en la semiótica de la cultura. Revista de Occidente, n. 316, p. 62-75, 2007.

MEZZADRA, Sandro. Derecho de fuga. Migraciones, ciudadanía y globalización. Madrid: Traficantes de sueños. Mapas, 2005.

MEZZADRA, Sandro; NEILSON, Brett. La frontera como método. Madrid: Traficantes de Sueños, 2017.

MOCHEL, France. La agenda Tampere: hacia una política europea de inmigración. CIDOB, p. 136-152, 2004. 
MORA, Belvy; MONTENEGRO, Marisela. Fronteras internas, cuerpos marcados y experiencia de fuera de lugar. Las migraciones internacionales bajo las actuales lógicas de explotación y exclusión del capitalismo global. Athenea Digital, n. 15, p. 1-19, 2009.

NARANJO, Gloria. Desterritorialización de fronteras y externalización de políticas migratorias. Flujos migratorios irregulares y control de las fronteras exteriores en la frontera España-Marruecos. Estudios políticos, n. 45, p. 13-32, 2014.

NEWMAN, David. On borders and power: A theoretical framework. Journal of Borderlands Studies, n. 18, p. 13-25, 2003.

NEWMAN, David. The lines that continue to separate us: borders in our 'borderless' world. Progress in Human Geography, n. 30, p. 1-19, 2006.

O'NEILL, Onora. Justice and Boundaries. In: BROWN, Chris (ed.). Political Restructuring in Europe: Ethical Perspectives. Londres: Routledge, 1994, p. 69-88.

OHMAE, Kenichi. The Borderless World. Nueva York: Harper Collins, 1990.

OLMOS, Antonia. La población inmigrante extranjera y la construcción de la diferencia. Discursos de alteridad en el sistema educativo andaluz. (Tesis Doctoral). Granada: Universidad de Granada, 2009.

ORTEGA-PÉREZ, Nieves. España: Hacia una nueva política migratoria. Migration Information Source, 2003. Disponible en: < http://www.migrationpolicy.org/ article/espa\%C3\%B1a-hacia-una-nueva-pol\%C3\%ADtica-migratoria >. Acceso en: 22.04.2017.

PAPADOPOULOS, Dimitris; STEPHENSON, Niamh; TSIANOS, Vassilis. Escape routes: control and subversion in the twenty-first century. London: Pluto Press, 2008.

PEDONE, Claudia. Globalización y migraciones internacionales. Cadenas y redes. Barcelona: Universidad Autónoma de Barcelona, 2001.

PÉREZ, Antía. La evolución reciente de las políticas de control migratorio en España. In: IZQUIERDO, Antonio; CORNELIUS, Wayne (eds.). Políticas de control migratorio. Barcelona: Bellaterra, 2012, p. 143-211.

PINYOL, Gema ¿Una oportunidad perdida? La construcción de un escenario euroafricano de migraciones y su impacto en las fronteras exteriores de la Unión Europea. In: ZAPATA-BARRERO, Ricard; GALLARDO-FERRER, Xavier (eds.). Fronteras en movimiento. Migraciones hacia la Unión Europea en el contexto Mediterráneo. Barcelona: Bellaterra, 2012, p. 255-280.

PORCAUSA. La franquicia antimigración. Cómo se expande el populismo xenófobo en Europa. Madrid: Fundación PorCausa, 2019.

QURAISHI, Muzammil. Muslims and crime: A comparative study. Hampshire: Ashgate Publishing, 2005.

REMIRO-BROTÓNS, Antonio. Unión Europea-Marruecos. ¿Una vecindad privilegiada? Madrid: Academia Europea de Ciencias y Artes, 2012.

RIEZU, Jorge. Para una teoría de la frontera y otros ensayos. Salamanca: Editorial Esteban, 2008.

RIGO, Enrica. Europa di confine. Trasformazioni della cittadinanza nell'Unione allargata. Roma: Meltemi, 2007. 
RODRÍGuEZ, Roxana. Cartografía de las fronteras. Diario de campo. México: Roxana Rodríguez Ortiz, 2016.

ROSADO-CARO, Ana M.; LARA, Rafael. Derechos Humanos en la Frontera Sur. APDHA: Sevilla, 2019.

SACEDA, Marta. Evolución de las migraciones entre Marruecos y España (1999-2014): la gestión migratoria en Ceuta ante la encrucijada de intereses UE-Marruecos. (Tesis Doctoral). Madrid: Universidad Complutense de Madrid, 2016.

SANTAMARÍA, Enrique. La Incógnita del extraño: una aproximación a la significación sociológica de la "inmigración no comunitaria". Barcelona: Anthropos, 2002.

SASSEN, Saskia. Cities in a World Economy. Thousand Oaks: Pine Forge Press, 2000.

SASSEN, Saskia. Contrageografías de la globalización. Género y ciudadanía en los circuitos transfronterizos. Madrid: Traficantes de Sueños. Mapas, 2003.

SASSEN, Saskia. Una sociología de la globalización. Buenos Aires: Katz Editores, 2007.

SASSEN, Saskia. Territorio, autoridad y derechos. Buenos Aires: Katz Editores, 2010.

SASSEN, Saskia. Inmigrantes y ciudadanos. De las migraciones masivas a la Europa fortaleza. Madrid: Siglo XXI Editores, 2014.

SORIANO-MIRAS, Rosa; TRINIDAD, Antonio; BARROS, Francisco. Las fronteras de la economía global localizada. El caso hispano-marroquí. In: TRINIDAD, Antonio; SÁNCHEZ, Mariano (eds.). Marcos de análisis de los problemas sociales. Madrid: La Catarata, 2016, p. 279-296.

SPENCER, Michael. 1992 and All That: Civil liberties in the balance. Londres: Civil Liberties Trust, 1990.

TAPIA, Marcela; GONZÁLEZ, Adriana. Fronteras, regiones fronterizas y migraciones. Entre apertura, integración y cierre. In: TAPIA, Marcela; GONZÁLEZ, Adriana (comps.). Regiones fronterizas, migración y los desafíos para los Estados Nacionales Latinoamericanos. Santiago de Chile: Ril editores, 2014, p. 17-40.

VELASCO, Juan Carlos. Dejando atrás las fronteras. Las políticas migratorias ante las exigencias de la justicia global. Arbor, n. 744, p. 585-601, 2010.

VELASCO, Juan Carlos. Movilidad humana y fronteras abiertas. Claves de Razón Práctica, n. 219, p. 28-35, 2012.

WHITE, Gregory. La migración laboral marroquí y los territorios españoles de Ceuta y Melilla. Revista Internacional de Sociología, n. 36, p. 135-168, 2003.

ZAPATA-BARRERO, Ricard. Shaping the normative contours of the European Union: A migration-border framework. Barcelona: Fundación CIDOB.

ZAPATA-BARRERO, Ricard. Teoría Política de la Frontera y la movilidad humana. Revista Española de Ciencia Política, n. 29, p. 39-66, 2012.

ZAPATA-BARRERO, Ricard; FERRER-GALLARDO, Xavier. Introducción. Las fronteras en la época de la movilidad. In: ZAPATA-BARRERO, Ricard; FERRER-GALLARDO, Xavier (eds.). Fronteras en movimiento. Migraciones hacia la Unión Europea en el contexto Mediterráneo. Barcelona: Bellaterra, 2012, p. 11-26.

ZOLBERG, Aristide. Contemporary transnational migrations in historical perspective: patterms and dilemmas. In: KRITZ, Mary (ed.). U.S. immigration and refugee policy: global and domestic issues. Lexington: Lexington Book, 1983, p. 15-21. 